\title{
Brazilian red propolis: legitimate name of the plant resin source
}

\begin{abstract}
Red propolis ranks as the second most produced Brazilian propolis type. Its main chemical constituents are phenolic substances typical of the subfamily Faboideae of the Fabaceae (Leguminosae) family, such as neoflavanoids, chalcones, flavanones and isoflavonoids, among them isoflavones (e.g. biochanin a, daidzein) and pterocarpans (e.g. medicarpin). The plant source of Brazilian red propolis has been referred to as Dalbergia ecastophyllum throughout the propolis literature. Such scientific binomial, however, is a synonym of the legitimate name Dalbergia ecastaphyllum.
\end{abstract}

Keywords: botanical origin, brazilian propolis, dalbergia ecastaphyllum, isoflavonoids, legitimate name, medicarpin, neoflavonoids, phenolic compounds, synonym
Volume 6 Issue I - 2018

\author{
Antonio Salatino Maria Luiza F Salatino \\ Department of Botany, Institute of Biosciences, University of \\ São Paulo, Brazil
}

Correspondence: Antonio Salatino, Department of Botany, Institute of Biosciences, University of São Paulo, Rua do Matão 277, 05508-090, São Paulo, SP, Brazil, Tel (+55II)309I-7532, Email asalatin@ib.usp.br

Received: January 03, 2018| Published: January 08, 2018

\section{Introduction}

Propolis is a product from honey bee hives, containing chiefly beeswax and a resin obtained from diverse plant sources, such as apical buds, young leaves and exudates. Color, smell and texture vary according to propolis types and plant sources. Beginning in the last decade of the last century the number of publications about propolis escalated, giving rise to successive reviews about propolis chemistry, botanical origin and biological properties. ${ }^{1-3}$ A wide spectrum of biological activities of propolis has been revealed, such as antimicrobial, anti-inflammatory, antitumor, immune-modulating and wound-healing. ${ }^{4,5}$ Concomitantly, the interest in the medicinal and nutritional properties of propolis expanded among people from several countries, such as Japan, China, Russia, France, Germany and Brazil. The pharmaceutical and cosmetic industry took advantage of the promising new market. Hence, in several countries there is at present a wide diversity of commercial products containing propolis, such as tinctures, sprays, candies, ointments, soaps, toothpastes and creams for the skin. A highly active and expanding domestic and international trade of Brazilian propolis is in operation. Propolis market size in Japan was estimated at US \$3 billion in 2009, with a substantial fraction derived from Brazilian products. ${ }^{6}$

Propolis constituents bearing biological activity are all derived from resins that the honey bees collect form plant buds or exudates. The identification of the plant sources of resin is crucial for the full characterization of propolis types and their standardization. ${ }^{7}$ Biologically active substances from most propolis types correspond to phenolics, such as flavonoids (European propolis, derived from Populus species), prenylated phenylpropanoids (Brazilian green propolis, derived from Baccharis dracunculifolia) and polyprenylated benzophenonones (Venezuelan propolis, derived from Clusia species).

The Brazilian propolis type most produced is the green type, from the Southeast and Central-West regions. It is derived from buds, leaf primordia and young leaves of Baccharis dracunculifolia (Asteraceae). ${ }^{8}$ Prenylated phenylpropanoids (e.g. artepillin c) and caffeoylquinic acids predominated as its main constituents. Brazilian green propolis is consumed domestically and exported to several countries, mainly to Japan and China.

\section{Brazilian red propolis}

This type of propolis was chemically and botanically characterized almost concomitantly by two independent publications. ${ }^{9,10}$ Since then, several biological properties of Brazilian red propolis have been reported, such as antioxidant, antimicrobial, cytotoxic and antitumor. ${ }^{11,12}$ Commercial production of the new type of propolis rapidly increased, while consumption escalated both domestically and internationally. Presently, it is the second most produced and traded type of Brazilian propolis, being produced mainly on the littoral of the state of Alagoas (northeast Brazil). Chemical constituents reported from Brazilian red propolis correspond to isoflavones (e.g. daidzein, formononetin and biochanin a), pterocarpans (e.g. medicarpin), neoflavonoids, chalcones and flavonols. ${ }^{9-12}$ The characteristic red color of the product is due to pigments called retusapurpurins. ${ }^{13}$ Some of the red propolis constituents, such as chalcones, neoflavonoids, isoflavones and pterocarpns, are classes of secondary metabolites characteristic of the subfamily Faboideae of the family Fabaceae (Leguminosae).

\section{Plant source of red propolis resin}

Chemical studies and observations of honey bee behavior have determined the botanical origin of Brazilian red propolis: it is a red resin that exudes from wounds caused by insects feeding on stems of a woody climber or prostrate plant of the genus Dalbergia (Fabaceae, Faboideae). The species occurs on restingas (vegetation growing on sandy soil close to the sea) and mangroves, extending from the state of Santa Catarina (southern Brazil) to the northeastern and northern Brazil, as well as Caribbean islands. The species has been referred to as Dalbergia ecastophyllum by many Brazilian botanists. This name was also used to designate the plant source of resin in the first publications about Brazilian red propolis,,${ }^{910}$ Thereafter, the name has spread to all papers dealing with this type of Brazilian propolis. 


\section{Legitimate name of the plant}

The origin of the name of the plant that provides resin for production of Brazilian red propolis may be traced by searches at http:// www.ipni.org or http://tropicos.org. The basionym of the species is Hedysarum ecastaphyllum, a name created by Linnaeus. In 1894, the species was transferred to the genus Dalbergia by Paul HW Taubert. Hence the complete legitimate name of the species is Dalbergia ecastaphyllum (L.) Taubert. However, in his original publication of the species, Taubert annotated the binomial Dalbergia ecastophyllum, which probably led most botanists to adopt an illegitimate name for the species. On the other hand, the legitimate name has appeared in several publications dealing with themes other than propolis, e.g. Flora de Santa Catarina ${ }^{14}$ and a review of the Brazilian species of Dalbergia. ${ }^{14,15}$

\section{Conclusion}

Further literature dealing with Brazilian red propolis should take care to refer to the botanical origin of the propolis type by the legitimate name Dalbergia ecastaphyllum.

\section{Acknowledgements}

The authors are fellow researchers of CNPq (Conselho Nacional do Desenvolvimento Científico e Tecnológico, Brazil).

\section{Conflict of interest}

The authors declare that they have no conflict of interest.

\section{References}

1. Marcucci MR. Propolis: chemical composition, biological proprieties and therapeutic activity. Apidologie. 1995;26(2):83-99.

2. Bankova V. Recent trends and important developments in propolis research. Evid Based Complement Alternat Med. 2005;2(1):29-32.

3. Salatino A, Fernandes-Silva CC, Righi AA, et al. Propolis research and the chemistry of plant products. Nat Prod Rep. 2011;28(5):925-936.
4. Sforcin JM. Biological properties and therapeutic applications of propolis. Phytother Res. 2016;30(6):894-905.

5. Zabaiou N, Fouache A, Trousson A, et al. Biological properties of propolis extracts: something new from an ancient product. Chem Phys Lipids. 2017;207(Pt B):214-222.

6. Toreti VC, Sato HH, Pastore M, et al. Recent progress of propolis for its biological and chemical composition and its botanical origin. Evid Based Complement Alternat Med. 2013;2013:697390.

7. Bankova V. Chemical diversity of propolis and the problem of standardization. J Ethnopharmacol. 2005;100(1-2):114-117.

8. Teixeira EW, Negri G, Meira RMSA, et al. Plant origin of green propolis: bee behavior, plant anatomy and chemistry. Evid Based Complement Alternat Med. 2005;2(1):85-92.

9. Daugsch A, Moraes DS, Fort P, et al. Brazilian red propolis-chemical composition and botanical origin. Evid Based Complement Alternat Med. 2008;5(4):435-441.

10. Silva BB, Rosalen PL, Cury JA, et al. Chemical composition and botanical origin of red propolis, a new type of Brazilian propolis. Evid Based Complement Alternat Med. 2008;5(3):313-316.

11. Li F, Awale S, Tezuka Y, et al. Cytotoxic constituents from Brazilian red propolis and their structure-activity relationships. Bioorg Med Chem. 2008;16(10):5434-5440.

12. Righi AA, Alves TR, Negri G, et al. Brazilian red propolis: unreported substances, antioxidant and antimicrobial activities. J Sci Food Agric. 2011;91(13):2363-2370.

13. da Silva Frozza CO, Garcia CSC, Gambato G, et al. Chemical characterization, antioxidant and cytotoxic activities of Brazilian red propolis. Food Chem Toxicol. 2013;52(1):137-142.

14. Flora de Santa Catarina; 2017.

15. Carvalho AM. A synopsis of the genus Dalbergia (Fabaceae: Dalbergieae) in Brazil. Brittonia. 1997;49(1):87-109. 